\title{
PARALLEL POLYMORPHISM IN AUSTRALIAN FROGS OF THE GENUS RANIDELLA
}

\author{
C. MICHAEL BULL* \\ Department of Zoology, University of Western Australia, Nedlands, \\ Western Australia 6009
}

Received : 29.iv.75

\begin{abstract}
SUMMARY
Two common back-pattern morphs are known in seven species of the genus Ranidella in Australia. Inheritance patterns of crosses within and between the two species $R$. pseudinsignifera and $R$. insignifera are investigated. The results indicate that the loci involved occupy homologous positions in the two genomes, and have analogous, if not identical, alleles. It is suggested that the polymorphism was present in an ancestral stock species before these two taxa differentiated.
\end{abstract}

\section{INTRODUGTION}

SEveral recent studies have been made of the phenomenon of parallel polymorphisms of external markings in congeneric species (Hallka and Lallukka, 1969; Neck, 1973; Milstead, Rand and Stewart, 1974) with comments on the probable homologous nature of the inheritance patterns of variant morphs.

In a group of Australian leptodactylid frogs of the genus Ranidella (recently removed by Blake (1973) from the genus Crinia) seven species are known with similar discontinuous variability of dorsal patterning (Main, 1968). Two common morphs are recognised, their identity being based on the texture of the dorsal surface (Main, 1965). Individuals of the ridged morph have two raised ridges usually running along the entire dorsal body surface on either side of the mid-dorsal line. Associated with the ridges are two dark dorso-lateral stripes running from the shoulders to the ilia. The lyrate morph has a pair of raised crescentic ridges on either side of the mid-dorsal line on the dorsal surface over the scapular region, and sometimes another pair of crescents over the pelvic region. The background colour of the lyrate morph varies from plain to mottled brown, and sometimes the dorsal surface is covered with warty lumps. These two morphs are known to occur in Ranidella signifera, $R$. parinsignifera, $R$. pseudinsignifera, $R$. insignifera, $R$. subinsignifera, $R$. glauerti and $R$. tinnula (Main, 1968). Crinia georgiana, a species in a closely related genus (Blake, 1973), also exhibits these and other dorsal pattern variants.

Main (1965) presented data from 20 crosses between the two morphs of the Western Australian species $R$. insignifera, and suggested a single locus, two allele model for the inheritance of back-pattern morph. In his model ridged animals were homozygous recessives while lyrates were either heterozygotes or homozygous for the dominant allele. He also described three crosses within a second Western Australian species $R$. pseudinsignifera, which were consistent with this hypothesis. Bull (1973) showed that these

* Present address: School of Biological Sciences, Flinders University, Bedford Park, South Australia 5042. 
two species were genetically compatible. Progeny from $F_{1}$ hybrid crosses and backcrosses showed no significant reduction in survival to metamorphosis compared to controls. The opportunity then arises for testing whether or not the inheritance systems of these two species are homologous, and for postulating the age and origin of the polymorphism itself. If the loci involved in the two species occupy the same position in the two genomes, and the alleles are equivalent, then the inheritance patterns shown in hybrid offspring should be the same as those from within-species crosses.

In the years 1971 and 1972 over 400 crosses were made between and within these two species. From 135 of the crosses with parents of known morph, the phenotypes of 1379 metamorphosed offspring were recorded to investigate the homologies of the two polymorphisms.

\section{METHODS}

$R$. insignifera and $R$. pseudinsignifera have abutting allopatric distributions in Western Australia with a narrow hybrid zone at some points of contact (Littlejohn, 1959; Bull, 1973). The crosses were made using females collected in amplexus and either amplexed or chorusing males. Specimens of $R$. insignifera were taken from six populations east and south-east of Perth, and within $50 \mathrm{~km}$ of that city. Specimens of $R$. pseudinsignifera were collected from seven populations, all less than $100 \mathrm{~km}$ east of Perth. All of these populations were judged to be beyond the influence of the narrow hybrid zone, on the basis of a subjective evaluation of male mating call structure (Bull, 1973).

Crosses were made in the laboratory by stripping eggs from females into finger bowls of sperm suspension, following the method of Rugh (1948). Fertilised eggs were kept in the laboratory until hatching when 30 tadpoles from each cross were transferred to 3.5 litre capacity plastic bowls and placed in an outdoor situation. The tadpoles developed in these bowls by browsing on the natural algal growth. Daily checks were made to record individual phenotypes as metamorphosis took place.

\section{REsUlTs}

Data for all crosses are summarised in table 1. Numbers of ridged and lyrate offspring were analysed to test agreement with expected values based on the one locus model.

TABLE 1

Segregation of back-pattern morphs: combined data from all experimental crosses

\begin{tabular}{|c|c|c|c|c|}
\hline \multicolumn{2}{|c|}{ Parent species } & \multicolumn{3}{|c|}{$q \mathrm{r} \times \sigma^{7} \mathrm{r}$} \\
\hline$q$ & o & $n$ & 1 & $\mathbf{r}$ \\
\hline insig & insig & 12 & 0 & 100 \\
\hline pseud & pseud & 4 & 0 & 51 \\
\hline insig & pseud & 4 & 0 & 43 \\
\hline pseud & insig & 0 & - & - \\
\hline
\end{tabular}

$\overbrace{n} \begin{array}{ccr}1 & \mathrm{r} \\ 13 & 124 & 8 \\ 21 & 191 & 19 \\ 14 & 147 & 11 \\ 16 & 110 & 8\end{array}$

\begin{tabular}{|c|c|c|}
\hline \multicolumn{3}{|c|}{$q \mathbf{r} \times \delta^{71}$} \\
\hline$n$ & 1 & $\mathbf{r}$ \\
\hline 4 & 16 & 22 \\
\hline 4 & 45 & 33 \\
\hline 10 & 64 & 25 \\
\hline 7 & 62 & 33 \\
\hline
\end{tabular}

$\overbrace{n}$\begin{tabular}{ccc}
1 & \multicolumn{1}{c}{$r$} \\
5 & 38 & 17 \\
5 & 40 & 4 \\
5 & 35 & 14 \\
11 & 83 & 35
\end{tabular}

$n=$ number of crosses analysed $; 1=$ lyrate $; \mathrm{r}=$ ridged $;$ insig $=R$. insignifera $;$ pseud $=$ $R$. pseudinsignifera. 


\section{(i) Ridged $\times$ ridged crosses}

From 20 crosses all metamorphosing offspring were ridged. This is the expected result of the model which suggests that ridged frogs are homozygous for the recessive allele. The crosses between the two species showed exactly the same pattern.

\section{(ii) Lyrate $\times$ lyrate crosses}

If the lyrate condition is controlled by a dominant allele the exact genotype of the lyrate parents cannot be determined. In a cross one or both parents could be homozygous, in which case all the offspring would

TABLE 2

Observed and expected numbers of ridged offspring in crosses giving segregating offspring

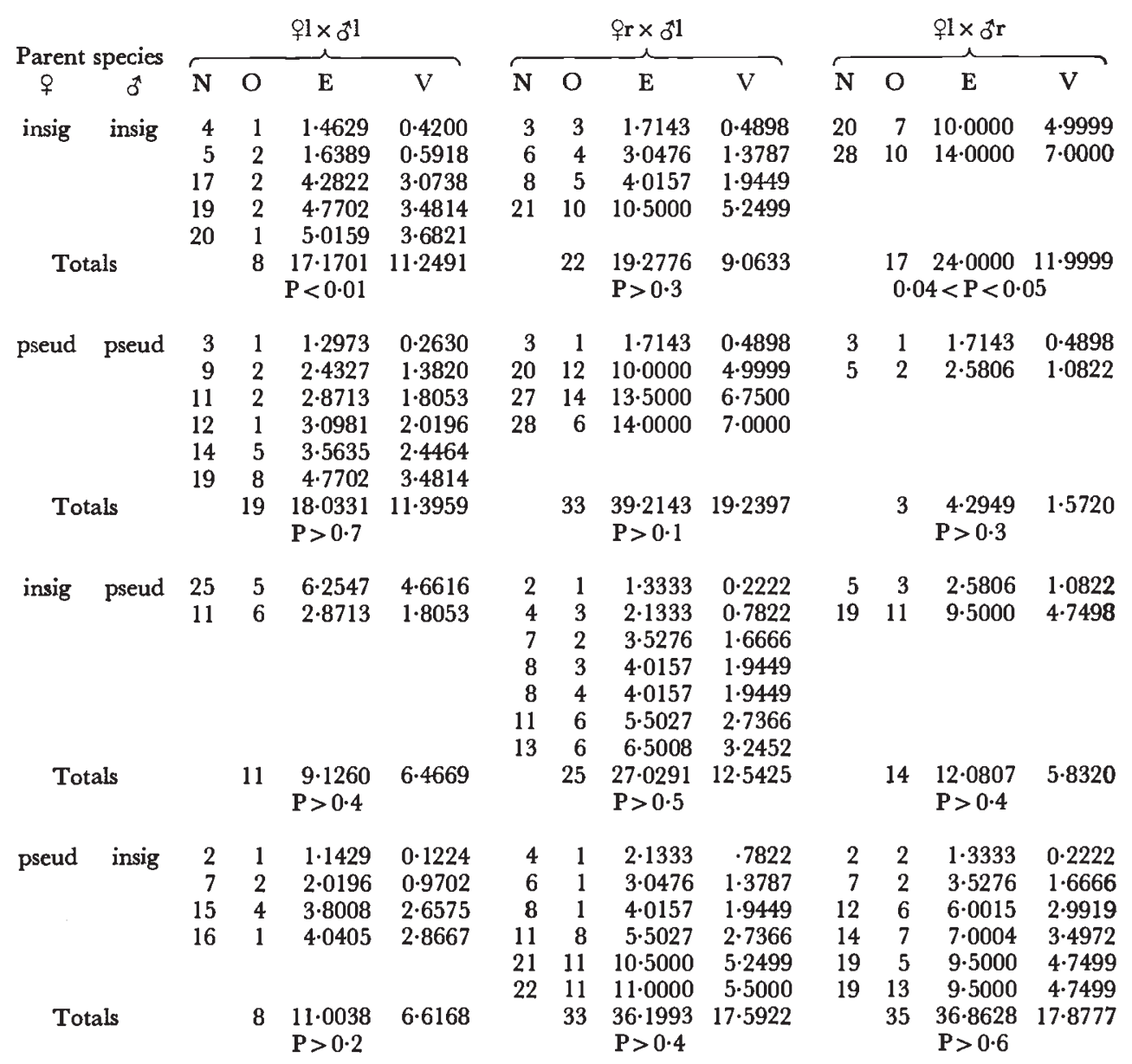

$\mathrm{N}=$ number of offspring surviving to metamorphosis from one cross; $\mathrm{O}=$ the observed number of ridged offspring in that cross; $\mathrm{E}$ is the mean number of ridged offspring expected in a family of size $\mathrm{N}$; $\mathrm{V}$ is the variance of this mean ( $\mathbf{E}$ and $\mathrm{V}$ calculated following Smith (1955)); $\mathbf{P}=$ probability based on null hypothesis of equality of $\mathrm{O}$ and $\mathrm{E}$. Other symbols as in table 1 . 
be expected to be lyrate. Alternatively both parents may be heterozygotes, giving offspring segregating in the ratio three lyrate to one ridged.

If only segregating families are considered in a test of goodness-of-fit to this expected ratio, a bias is introduced by the possible omission of heterozygote $\times$ heterozygote crosses which do not produce any ridged offspring. Instead use is made of a statistical test described by Smith (1955) in which expected numbers of recessive offspring in families with at least one recessive offspring are derived from a truncated binomial distribution (table 2).

In all crosses, except those within $R$. insignifera, the observed numbers of ridged progeny do not differ significantly from the values expected from the one locus model. The deviation from expectation within $R$. insignifera crosses can be attributed completely to one cross with one ridged and 19 lyrate offspring.

\section{(iii) Ridged female $\times$ lyrate male crosses}

Using the same test (table 2), there was no significant difference between observed and expected numbers of ridged offspring in either the withinspecies or the between-species crosses. The lyrate males used in the eight within-species crosses all must be heterozygotes since there was segregation in the progeny of each cross. A conventional chi-squared analysis is possible in this case and this confirms there were no significant deviations from equal ridged and lyrate offspring numbers in $R$. insignifera $\left(-\chi_{1}^{2}=0.94\right)$ or in $R$. pseudinsignifera $\left(-\chi_{1}^{2}=1 \cdot 85\right)$.

\section{(iv) Lyrate female $\times$ ridged male crosses}

The observed numbers of ridged offspring were not significantly different from expected in three of the four mating combinations (table 2). Crosses within $R$. insignifera produce significantly fewer ridged progeny than expected $(0.04<\mathrm{P}<0.05)$.

\section{(v) Backcrosses}

Four of the backcrosses performed with these species may be of some relevance in confirming the model of the genetic system. In 1971 a cross was made between a lyrate $R$. insignifera female and a ridged $R$. pseudinsignifera male. Only two tadpoles metamorphosed, both of which were lyrate, presumably heterozygotes. One of these, a male, survived until 1972 when its sperm was used in two backcrosses. The first was to a ridged $R$. insignifera female, resulting in one ridged juvenile, and the second cross was to a lyrate $R$. insignifera female from which three ridged and 29 lyrate offspring survived to metamorphosis. These results are consistent with the single locus model.

A lyrate $R$. insignifera male was presumed to be a homozygote because a cross with a ridged $R$. insignifera female produced nine lyrate offspring. This same male was also crossed to a lyrate female $R$. pseudinsignifera to produce 16 lyrate juvenile hybrids. A male from amongst these hybrids survived to maturity the following year when it was crossed to each of two lyrate female $R$. pseudinsignifera. The first cross resulted in three ridged and 16 lyrate progeny and the second, one ridged and four lyrate progeny. These 
results are compatible with the single locus model if we assume that all three lyrate $R$. pseudinsignifera females were heterozygotes.

\section{Discussion}

In the original model (Main, 1965) the inheritance of back-pattern polymorphism in $R$. insignifera is controlled by two alleles at a single locus, a dominant allele determining the lyrate morph, and a recessive allele the ridged morph. The data from crosses within $R$. insignifera in this study can be explained by the same model. The excess of the lyrate morph in two of the four crossing classes may be the result of differential mortality. The overall survival of tadpoles to metamorphosis in this study was less than 40 per cent (Bull, 1973).

The data from crosses within $R$. pseudinsignifera in this study show that an identical genetical system can account for the inheritance of back pattern in that species. Main (1965) made five crosses within $R$. glauerti, which also are consistent with the proposed genetical control system.

The inheritance patterns shown in the matings between $R$. insignifera and $R$. pseudinsignifera suggest that the two loci involved occupy homologous positions in the respective genomes, and have analogous, if not identical, alleles. If the two polymorphic systems were controlled at non-homologous loci then we might expect between-species crosses to produce the intermediate phenotypes familiar in many studies of hybridisation in anurans (e.g. Mecham, 1960; Martin, 1972). The alternative interpretations remaining are: (1) that the polymorphisms have a common origin in the ancestral stock species; (2) that mutations giving rise to the same polymorphism at the same locus have arisen independently in the two species following their separation; or (3) that introgressive hybridisation has allowed a polymorphism to be transferred from one species to the other after secondary contact. If we can assume that the homology of inheritance demonstrated for $R$. pseudinsignifera and $R$. insignifera is consistent in all other polymorphic members of this group, then it can be argued that the last two interpretations are most improbable.

The three species, $R$. pseudinsignifera, $R$. insignifera and $R$. subinsignifera, are considered to have arisen as three successive migrations to south-western Australia during Pleistocene pluvial periods, of a south-eastern stock now represented by $R$. parinsignifera (Main, Lee and Littlejohn, 1958; Main, 1968; Littlejohn, 1961, 1967). These four species have the same back pattern polymorphism, as do the species $R$. signifera and $R$. glauerti the western and eastern members of another group, genetically incompatible with species in the first group (Main, 1968). The independent establishment of mutations with the same phenotypic expression at the same loci in all of these species is unlikely.

Introgressive hybridisation could account for the homology between $R$. insignifera and $R$. pseudinsignifera (which have a narrow zone of hybridization (Littlejohn, 1957, 1959; Bull, 1973)), but such a process could not explain the parallel polymorphisms in geographically isolated or genetically incompatible pairs of species.

The most likely explanation of the homology of back-pattern polymorphism in this group of species is that it was present in an ancestral stock 
species. Main, Lee and Littlejohn (1958) have suggested that $R$. pseudinsignifera became separated during the Mindel glaciation, over 400,000 years ago, from the stock species which would later produce $R$. insignifera. The polymorphism was probably present even earlier, at the late Pliocene, when it is proposed (Main, Lee and Littlejohn, 1958) $R$. signifera and $R$. glauerti became a separate group.

Of the eight species placed in the " signifera group " of the genus Ranidella by Blake (1973), only $R$. sloanei does not show back-pattern polymorphism (Littlejohn, 1958). This may be a secondary loss of an ancestral character. In all other species the polymorphism has persisted despite variation in environmental conditions over the ranges of the different species, and over time within any one species range (Littlejohn, 1967; Main, 1968). A frequency dependent selection, perhaps imposed by visual predation (Milstead, Rand and Stewart, 1974) may be an important force in maintaining this polymorphism.

Acknowledgments. - L. Schmitt pointed out to me the method for analysis of family data. B. A. Barlow, P. R. Baverstock, M. J. Littlejohn, G. C. Kirby, J. D. Roberts, L. Schmitt and G. F. Watson all read an early draft of the paper and gave much helpful criticism. This work was carried out while the author was holding a Commonwealth Postgraduate Research Award at the University of Western Australia.

\section{REFERENCES}

BLAKE, A. J. D. 1973. Taxonomy and relationships of myobatrachine frogs (Leptodactylidae): a numerical approach. Aust. F. Zool., 21, 119-149.

BULL, C. M. 1973. The interactions of two allopatric frog species at their common boundary. Unpublished Ph.D. thesis; University of Western Australia.

HALKKA, O., AND LALLUKKA, R. 1969. The origin of balanced polymorphism in the spittlebugs (Philaenus, Homoptera). Ann. Zool. Fenn., 6, 431-434.

Lirtlejohn, M. J. 1957. The biology of the genus Crinia Tschudi. Unpublished Ph.D. thesis, University of Western Australia.

Litrlejohn, M. J. 1958. A new species of the genus Crinia Tschudi from south east Australia. Proc. Linn. Soc. N.S.W., 83, 222-226.

LitTLejohn, M. J. 1959. Call differentiation in a complex of seven species of Crinia (Anura: Leptodactylidae). Evolution, 13, 452-468.

LtTtlejohn, м. J. 1961. Age and origin of some south-western Australian species of Crinia (Anura: Leptodactylidae). In Vertebrate Speciation (ed. W. F. Blair.) University of Texas Press: Austin.

LITTLEJOHN, M. J. 1967. Patterns of zoogeography and speciation in south-eastern Australian Amphibia. In Australian Inland Waters and their Fauna (ed. A. H. Weatherley). Australian National University Press: Canberra.

MAIN, A. R. 1965. The inheritance of dorsal pattern in Crinia species (Anura: Leptodactylidae). 7. Roy. Soc. W.A., 48, 60-64.

MAIN, A. R. 1968. Ecology, systematics and evolution of Australian frogs. Adv. Ecol. Res., $5,37-86$.

MAIN, A. R., LEE, A. K., AND LITTLEJOHN, M. J. 1958. Evolution in three genera of Australian frogs. Evolution, 12, 224-233.

MARTIN, A. A. 1972. Studies in Australian Amphibia. III. The Limnodynastes dorsalis complex (Anura: Leptodactylidae). Aust. F. Zool., 20, 165-211.

MECHAM, J. s. 1960 . Introgressive hybridization between two south-eastern tree frogs. Evolution, 14, 445-457.

MILSTEAD, W. W., RAND, A. S., AND STEWART, M. M. 1974. Polymorphism in cricket frogs: an hypothesis. Evolution, 28, 489-491.

NECK, R. W. 1973. Homologous polymorphism and niche equivalence in the butterfly genus, Chlosyne. Heredity, 31, 118-123.

RUGH, R. 1948. Experimental Embryology. Burgess Publ. Co., Minneapolis.

smrri, c. A. B. 1955. A test for segregation ratios in family data. Ann. Hum. Genet., 20 257-265. 